\title{
Conceitos de aprendizagem, cinema e Film Literacy no documentário Ilha das Flores (1989)
}

\author{
Pamela de Bortoli Machado \\ Fábio Nauras Akhras
}

\begin{abstract}
Resumo: Este artigo explora as potencialidades do cinema quando proposto por um viés de aprendizagem. De tal forma que utilizamos processos de aprendizagem vinculados a exemplos extraídos do filme, que são capazes de gerar algum tipo de aprendizado. A ideia é que a partir de fragmentos do documentário, aqui no caso ilustrado por Ilha das Flores (1989), possamos visualizar como pode ocorrer um diálogo entre o cinema e os preceitos do que chamamos de Filme-educação, bem como os processos de aprendizagem indicados por Akhras, resultando em uma exemplificação da potencialidade de aprendizagem pelo cinema e possibilidades de discussões para com o filme.
\end{abstract}

Palavras-chave: Cinema. Aprendizado. Filme-educação. Literacia.

\section{Concepts of learning, cinema and Film Literacy in the documentary Island of Flowers (1989)}

\begin{abstract}
This article explores the potential of cinema when proposed with the learning. So, we use learning processes linked to examples extracted from the film, that are able to generate some type of learning. The idea is that from fragments of the documentary, here in the case illustrated by Island of Flowers (1989), we can see how a dialogue between the cinema and the precepts of what we call Education film works, as well as the learning processes Indicated by Akhras, resulting in an exemplification of the potential of film learning and possibilities for discussions with the film.
\end{abstract}

Keywords: Documentary. Learning. Film-education. Literacy. 


\section{Introdução}

No século XXI aprendemos com o olhar. Tal afirmação é enfatizada pelo fato de que o mundo contemporâneo encontra-se permeado por imagens, resultantes da "Era de Entretenimento" cuja alfabetização visual encontra-se na cultura da imagem, "em que há um declínio dramático na taxa de alfabetização, uma perda de habilidades associadas com a argumentação racional, o pensamento linear e analítico e o discurso crítico e público" (KELLNER, 1995, p. 108).

A referência do autor está na necessidade de compreendermos a cultura da imagem, ao passo que devemos aprender a ler as imagens, decifrar seus códigos e nos aprofundarmos ao seu sentido de modo que isso possa ir ao encontro de um processo de aprendizagem. Isso implicaria em uma chamada "pedagogia da leitura de imagens", que, para Kellner, se trata de "aprender como apreciar, decodificar e interpretar imagens, analisando tanto a forma como elas são construídas e operam em nossas vidas, quanto o conteúdo que elas comunicam em situações concretas" (KELLNER, 1995, p. 109).

A partir dessa menção de Kellner procuramos sua possível relação com o cinema, já que o mesmo é formado por imagens que se desenvolvem a partir de uma narrativa audiovisual. $\mathrm{O}$ cinema obriga que seu espectador atente para ele de modo fixo, contemplando toda a cena. A imagem fílmica "significa a reunião de uma infinidade de dados simultaneamente, levando o espectador não a reduzi-los, mas a aceitar a imagem integralmente" (MCLUHAN, 1998, p. 351352). E, por esse viés, acreditamos que o cinema deve se estabelecer como uma ferramenta de aprendizagem, de modo que alguns paradigmas precisam ser quebrados para que essa nova cultura baseada na imagem possa ser ressignificada:

É imperativo que o sistema educacional ultrapasse sua notória resistência às inovações e sua atitude defensiva face à mídia, que a levam a identificar com o livro o melhor modelo pedagógico tradicional e a rotular o mundo audiovisual como o mundo da frivolidade, da alienação e da manipulação; a fazer do livro o âmbito da reflexão, da análise e da argumentação, diante de um mundo de imagens sinônimas de emotividade e sedução (MARTIN-BARBERO, 1999, p. 28).

\section{Visual Literacy: educação do olhar}

\subsection{Conceito e possíveis aplicações:}


Se traduzirmos literalmente o termo Visual Literacy, veremos que seu preceito se aproxima como sendo letramento visual. Entretanto, conceituaremos Visual Literacy como a "Educação do Olhar". Tal posicionamento nosso diz respeito ao fato de que as mensagens visuais deverão ir além de uma contemplação visual, ao passo que há necessidade de "compreensão, interpretação e avaliação" (BRISTOR; DRAKE, 1994), também com cunho critico e criativo.

Suas aplicações se detêm a tudo aquilo que é visual, não se detendo apenas às "mídias de massa" e novas tecnologias, mas sim se faz presente nas artes visuais, artes plásticas, gráficos, mapas, fotografia, etc. Como o cinema é uma arte audiovisual, o pontuamos nessa subárea da mídia-educação, detendo-se aqui à vertente do olhar. Sendo assim, vincularemos abaixo alguns processos que dizem respeito à Educação do Olhar na área do cinema, enunciando alguns possíveis "modos de ver".

\subsection{Os diferentes modos de ver}

Segundo Fantin (2006), existem diferentes modos de ver os filmes, e nesse fluxo de imagens, há possíveis interações e apropriações que podem abranger um cunho lúdico, bem como educativo-criativo.

A partir dessa ideia de que um filme pode ser apresentado, recebido e ser apropriado de diferentes formas, Casetti (2004, p. 28) ilustra uma série de leituras possíveis ao espectador:

- Modo espetacular: ver filme como um espetáculo, como entretenimento e distração;

- Modo ficcional: ver filme para fazer o espectador vibrar, sentir ao ritmo dos eventos, participar das vivências dos personagens;

- Modo fabulante: ver filme para extrair uma lição da mensagem proposta;

- Modo documentarizante: ver filme para informar-se sobre a realidade das coisas do mundo, filmes históricos, etnográficos e documentários;

- Modo argumentativo-persuasivo: ver filme para convencer, elaborar um discurso, filmes didáticos com fins educativos e escolares;

- Modo artístico: ver filme destacando a produção de um autor, filmes de arte;

- Modo estético: ver filme interessando-se pelo trabalho de imagens e sons, filmes experimentais;

- Modo energizante: ver filme para vibrar ao ritmo das imagens e dos sons sem preocuparse com conteúdos, filmes musicais e videoclipes; 
- Modo privado: ver filme que produz efeito de retorno à vivência pessoal ou de grupo a que se pertence, reforçando a identidade, como os vistos e realizados na escola, associações e centros culturais.

Notamos que alguns modos vão ao encontro do que pretendemos considerar como Educação do olhar. Para tanto, há necessidade de uma avaliação fílmica bem como a relação que se pode estabelecer na prática educativa. Poderia dessa forma, haver "um trabalho intermediário entre a sensibilidade e o entendimento a partir do cinema que pode ativar outras maneiras de olhar, de produzir, de representar e de ler o mundo" (FANTIN, 2009, p. 220).

Assim, observamos que os modos espetacular, ficcional e energizante seriam desfavoráveis, já que a pretensão desses se vincula ao cinema comercial (CASETTI, 2004). E, todos os outros poderiam ser trabalhados como base de um exercício de Educação do Olhar devido a seus contextos e conteúdos, ou seja, "o texto que motiva a exploração do contexto, mas é o contexto que faz do texto aquilo que este é” (CASETTI, 2004, p. 284).

Tendo como motivação justamente o fato de que o filme é uma mídia-educação e seu contexto está relacionado ao exercício de uma Educação do olhar, salientaremos nos próximos itens algumas de suas formas atuantes, uma vez proposta a análise fílmica vinculada a alguns processos de aprendizagem, citados por Akhras (2010). Com isso, propomos reflexão de como o filme, aqui focado no documentário Ilha das Flores, pode provocar diferentes modos de ver, de ler, de pensar e, principalmente, de se aprender.

\section{Sobre o documentário Ilha das Flores (1989)}

O documentário Ilha das Flores é uma produção de Mônica Schmiedt, Giba Assis Brasil, Nôra Gulart, com roteiro de Jorge Furtado.

Ilha das Flores é um local real, localizado à margem esquerda do Rio Guaíba e a poucos quilômetros de Porto Alegre. Para lá é levada grande parte do lixo produzido na capital, e este lixo é depositado num terreno de propriedade de criadores de porcos. Logo que o lixo é descarregado dos caminhões, os empregados separam parte dele para o consumo dos porcos. Durante este processo começam a se formar filas de crianças e mulheres do lado de fora da cerca, à espera da sobra do lixo, que utilizam para alimentação. Como a filas são muito grandes, os empregados organizam grupos de pessoas que, num tempo estipulado de cinco minutos, podem 
pegar que conseguirem do lixo. Acabado o tempo, este grupo é retirado do local, dando lugar ao próximo grupo (CASACINEPOA, 2017).

O curta apresenta a trajetória de um tomate, desde a colheita ao descarte por uma dona de casa, até a chegada ao lixão da ilha, onde crianças disputam alimentos que sequer serviam de alimento para os porcos. A partir da trajetória do tomate, o curta faz uma crítica à desigualdade social, de forma satírica e chocante. E tal choque se dá pelas condições de vida das pessoas que vivem na extrema pobreza na Ilha das Flores. O documentário se propõe a apresentar a precariedade alimentar dessas pessoas com o objetivo de tocar o emocional de quem o assiste, formulando assim uma conscientização social.

\subsection{A ideia central do filme e suas provocações}

A ideia do filme é mostrar o absurdo desta situação: seres humanos que, numa escala de prioridade, se encontram depois dos porcos. Mulheres e crianças que, num tempo determinado de cinco minutos, garantem na sobra do alimento dos porcos sua alimentação diária. Esta situação absurda será mostrada de uma forma absurda.

Mesmo com a estabilidade emocional presente na voz do narrador, o documentário emociona pelas imagens impactantes que apresenta. Os resultados de uma economia consumista capitalista e seu descompasso são as consequências manifestadas na Ilha das Flores. Todo o enredo do documentário que fortemente enfatiza a estrutura de um ser humano que possui o telencéfalo altamente desenvolvido e o polegar opositor serve para mencionar que até mesmo os animais como os porcos, que não possuem tal estrutura, ganham mais destaque do que outros seres humanos. 
Quadro 1 - Ficha técnica do filme Ilha das flores

Gênero: Documentírio
Direção: Jorge Furtado
Roteiro: Jorge Furtado
Elenco: Ciça Reckziegel, Júlia Barth, Paulo José
Produção: Monica Schmiedt, Nora Goulart
Fotografia: Roberto Henkin, Sérgio Amon
Trilha Sonora: Geraldo Fach
Duraçâo: 13 min.
Ano: 1989
País: Brasil
Cor: Colorido
Estúdio: Caśa de Cinema de Porto Alegre

Fonte: Disponível em: 〈http://portacurtas.org.br〉. Acesso em: 28 ago. 2017

\section{Processos de aprendizagem na análise de Ilha das Flores}

"Na sala de aula, como em qualquer espaço educativo, o cinema é um rico material didático. Agente socializante e socializador, ele desperta interesses teóricos, questionamentos sociopolíticos, enriquecimento cultural” (SOUZA, 2011, p. 9). Com este posicionamento de Souza, acreditamos nas potencialidades que o filme possui em sala de aula. A partir de uma análise fílmica, possibilitamos algumas ideias de como o filme pode ir além de sua visualização, uma vez vinculado a processos de aprendizagem.

Ao identificarmos o cinema como a representação de realidades, podemos aproximá-lo com atividades criativas e culturais a serem desenvolvidas em sala de aula. Para Duarte (2002), esse potencial de impressão de realidade é valioso, uma vez que ele propicia prazerosamente, com os estudantes, avaliar, discutir, refletir, em um primeiro momento, sobre o próprio filme e o cinema. E, em um segundo momento, gera uma discussão sobre a vida - das pessoas, no geral, e a deles, mais especificamente, e a sociedade como o continente das vidas.

Já no quadro abaixo (LINHARES; PIMENTA, 2013, p. 51), podemos observar a ideia de um terceiro momento com o filme, no caso como sendo a reelaboração do que foi discutido, vivenciando, criando e socializando: 
Quadro 2-O que podemos fazer ao levar um filme para sala de aula

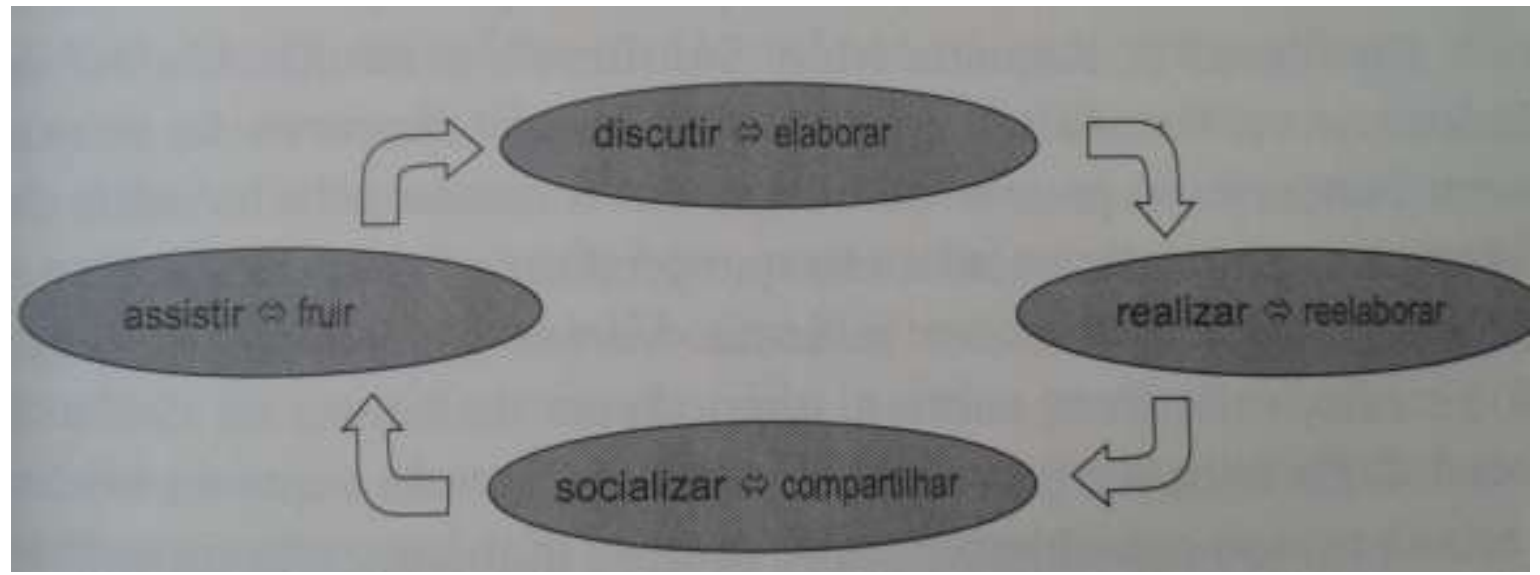

Fonte: LINHARES, M.; PIMENTA, M. A pequena Miss Sunshine. In: SAMPAIO, J. (Org.). Usando filmes nas aulas de arte. Curitiba: CRV, 2013. p. 51.

Segundo esse esquema apresentado, as autoras defendem a ideia de que os espectadores possuem a capacidade de se identificarem e se projetarem nas personagens, vivenciando psiquicamente suas emoções. Esses processos de projeção e identificação são explicados por Xavier como:

Atribuir a alguém características que nos são próprias. A identificação, por sua vez, é o seu oposto. O sujeito em vez de se projetar no mundo, absorve-o. Esses mecanismos acontecem, ao mesmo tempo, pois a mais banal projeção sobre outrem - o eu ponho-me no seu lugar - já é uma identificação de mim com o outro, identificação essa que facilita e convida a uma identificação do outro comigo: esse outro tornou-se assimilável. (XAVIER, 1983, p. 146).

Assim, por meio desses processos há a possiblidade de aproximação do filme com os estudantes, de maneira que isso viabiliza as possíveis discussões e atividades que serão realizadas a partir da temática e contexto fílmico. As autoras ressaltam que a temática do filme deve ser trabalhada antes de assisti-lo, para que a construção do contexto fílmico possua subsídios, além de esclarecer que o filme está representando uma pessoa e, novamente, o fato de que o filme deve ser lido e não apenas visto:

Depois de uma breve conversa sobre representações, os alunos estarão mais atentos e menos ingênuos para assistirem ao filme e posteriormente comentar sobre as representações presentes. É importante ressaltar que o modo como interpretamos o que vemos tem muito a ver com o nosso repertório cultural e os valores da época e local em que vivemos. O leitor ingênuo não percebe isso, mas um leitor crítico sim (LINHARES; PIMENTA, 2013, p. 58). 
Dessa maneira, descreveremos abaixo os processos de aprendizagem citados por Akhras (2010), propostos com a ideia de ir além de um simples olhar, indo para uma análise visual crítica que se destina a compreender o filme com uma leitura de sua imagética. Assim, vinculando tais processos com discussões e atividades possíveis em sala de aula, o filme expande sua função de produto audiovisual e passa a ocupar um instrumento de canalização de conhecimento e criatividade no aluno, ampliando sua capacidade crítica e discernimento, visto que sua cultura está conectada com a cultura da imagem.

Logo, através de trechos do documentário Ilha das Flores, exemplificaremos como alguns processos de aprendizagem se correlacionam com a imagética e de que forma o conhecimento pode ser construído a partir da narrativa assistida:

\subsection{Processos de perspectivas e conhecimento prévio a partir de um contexto.}

Tanto nesse processo quanto nos seguintes, Akhras (2010) os relaciona com situações constituídas de elementos que norteiam aprendizados e que contribuem para uma possível "educação do olhar":

Um aspecto central para a criação de um processo que facilite o aprendizado é determinar como uma sequência de situações pode ser elaborada para que elementos de situações anteriores possam se conectar com elementos de situações posteriores para provocar um aprendizado. Com isso, os modos particulares pelos quais elementos de uma situação se conectam com elementos de outra situação em uma sequência de situações que ocorre em um processo de aprendizado, caracterizam propriedades particulares desse processo de aprendizado (AKHRAS, 2010, p. 109-110).

Assim, veremos a seguir como agem esses modos particulares de processos de aprendizagem, inicialmente pelo contexto de perspectiva e conhecimento prévio, situados nas frases apresentadas no começo do filme:

- Situação 1: "Este não é um filme de ficção"; $\rightarrow$ O que será mostrado é real, por mais chocante ou grotesco que seja;

- Situação 2: "Existe um lugar chamado Ilha das Flores"; $\rightarrow$ Busca despertar o interesse do espectador como que tipo de lugar é ou o que acontece neste local;

- Situação 3: "Deus não existe". $\rightarrow$ Ataca o que é certeza para muitos, ainda mais sendo uma afirmação. E, mais uma vez o espectador pergunta-se: "Por que este tipo de coisa é dita?" "Por que atacar uma certeza absoluta de tantas pessoas?" 
A partir desse primeiro processo, observamos como o documentário pode remeter a possíveis indagações já nos minutos iniciais. As primeiras frases apresentadas pelo filme também prendem a atenção do estudante, uma vez que o documentário alerta ser baseado em fatos concretos e que os mesmos estão relacionados a um lugar real, a Ilha das Flores.

\subsection{Processos cumulativos no aprendizado}

Segundo Akhras (2010), nada tem significado ou é aprendido isoladamente. O autor se refere ao fato de que o conhecimento é baseado em situações prévias de aprendizado, que influenciarão em aprendizados sequentes. Isso significa que o processo de repetição se dá nessa formação de conhecimento, uma vez que o estudante, ao rever a mesma concepção de diferentes modos, constrói o seu conhecimento a partir do que lhe foi passado.

No documentário Ilha das Flores, observamos as seguintes situações que reafirmam a mesma ideia, de modos distintos:

- Situação 4: “Os seres humanos são animais mamíferos, bípedes, que se distinguem dos outros mamíferos como a baleia, ou bípedes como a galinha, principalmente por duas características: o telencéfalo altamente desenvolvido e o polegar opositor;"

- Situação 5: "A utilidade principal do tomate é a alimentação dos seres humanos";

- Situação 6: “O Sr. Suzuki é um japonês e, portanto, um ser humano”;

- Situação 7: “O porco é um mamífero como os seres humanos e as baleias, porém, quadrúpede. Serve de alimento aos japoneses (fazendo referência ao Sr. Suzuki), aos católicos (fazendo referência a dona Anete) e aos demais seres humanos, com exceção dos judeus."

- Situação 8: Descrição do lixo e a menção de que "o lixo é levado para determinados lugares, bem longe, para que possa livremente sujar, cheirar e atrair doenças".

O documentário insiste em colocações que são reforçadas pela imagem. E, mesmo quando há contraposição em imagem e afirmativa, isso também gera a formação de um contexto. Tal exemplo se dá com a cena de dizimação dos judeus, em que a voz do narrador, que nunca fica mais alta ou mais baixa, faz neste momento uma pausa para dizer que os judeus também são seres humanos enquanto corpos de judeus são atirados num buraco onde outros corpos de judeus apodrecem. 
Percebemos que essa ênfase na repetição é proposital e cumulativa, já que o desenrolar do documentário se baseia na ideia de que mesmo sendo todos os seres humanos iguais, não são vistos da mesma forma em face da desigualdade econômica, ou em tiranias, como o caso dos judeus.

\subsection{Processos de construção no aprendizado}

Akhras (2010) menciona como sendo a associação do conhecimento aprendido com uma nova experiência, ou a ressignificação e reinterpretação do que fora aprendido, mediante a nova experiência. Fazendo relação com o filme, podemos dizer que é quando a narrativa apresenta algo novo baseado no que já foi dito, possibilitando a compreensão de um todo. Além disso, a narrativa também pode contradizer ou ressaltar o que foi mencionado, para que assim o conhecimento seja desmistificado e construído de fato.

As situações do filme nessa classificação são:

- Situação 8: Fala do supermercado, para chegar até Dona Anete (que, segundo o narrador, é também um ser humano por possuir um telencéfalo altamente desenvolvido com o polegar opositor), uma mulher que, com o dinheiro vindo de seu trabalho na venda de perfumes, foi ao mercado comprar aqueles tomates cultivados na plantação do Sr. Suzuki. $\rightarrow$ Nesse momento o documentário já explicou o que é e como surgiu o dinheiro, reafirmando a ideia do consumismo;

- Situação 9: O narrador fala do lucro que Dona Anete tem com a compra e venda destes perfumes $\rightarrow$ Novamente a ressalva sobre como funciona a economia;

- Situação 10: “Alguns tomates que o Sr. Suzuki trocou por dinheiro com o supermercado e que foram trocados pelo dinheiro que Dona Anete obteve com o lucro na troca dos perfumes extraídos das flores, foram transformados em molho para a carne de porco." $\rightarrow$ Aqui o documentário faz uma revisão sobre como funciona a relação de compra/venda, além da repetição de que o porco é um mamífero que serve de alimento aos seres humanos;

- Situação 11: "Em Porto Alegre, um dos lugares escolhidos para que o lixo cheire mal e atraia doenças chama-se Ilha das flores." $\rightarrow$ Nesse momento há uma revisão sobre as flores utilizadas nos perfumes, e o desfecho do tomate do Sr. Suzuki que foi dispensado por dona Anete e que chegou à Ilha das Flores como alimento aos seres humanos.

Na situação 11 ocorre uma retomada sobre o lugar enunciado inicialmente. E a partir daí os dados mencionados desde o início do filme interligam-se. Desde a plantação do tomate, o 
capital, o consumismo, e a chegada ao lixo. Nesse momento a construção de conhecimentos se volta para o escancaramento da desigualdade social, com a desmistificação de que um lugar chamado de ilha é na verdade um depósito de lixo, e que as crianças que correm atrás do caminhão de lixo, na verdade correm atrás de sua alimentação.

\subsection{Processos de autorregulação e reflexão no aprendizado}

A partir dos processos de cumulação e construção, o estudante pode ser capaz de construir uma reflexão crítica sobre aquilo que está sendo apresentado pelo filme, por meio de seus próprios conhecimentos, juntamente com os conhecimentos que foram assimilados durante a experiência. Assim, já na parte final do filme, o estudante poderá ser capaz de refletir sobre os aspectos econômicos que o documentário apresentou, bem como as consequências da desigualdade social, o conceito de ser humano e o fato de que isso não é levado em conta numa sociedade capitalista, e que mesmo com telencéfalo altamente desenvolvido, o ser humano é capaz de se autodestruir.

As situações ilustradas pelo filme baseadas nesses processos são:

- Situação 12: "Há poucas flores na Ilha das Flores" $\rightarrow$ As flores coloridas e cheirosas utilizadas para o feitio do perfume que dona Anete vende não estão neste lugar; o que falta em flores, sobra em lixo;

- Situação 13: “Aquilo que foi considerado impróprio para a alimentação dos porcos, será utilizado na alimentação de mulheres e crianças." $\rightarrow$ O narrador explica que mulheres e crianças são seres humanos por possuírem o telencéfalo altamente desenvolvido e o polegar opositor e nenhum dinheiro. O dinheiro é o que faz a diferença entre estas pessoas e o dono dos porcos. É por causa do dinheiro que ele é o dono dos porcos, o dono do terreno e o patrão dos empregados que priorizam seus porcos e deixam para segundo plano as pessoas da Ilha das flores.

- Situação 14: Quando há a retomada da explicação que pontuou o filme "todo ser humano caracteriza-se por ter o telencéfalo altamente desenvolvido, o polegar opositor e por ser livre." Observamos o contraste entre a liberdade mencionada e a imagem do lixão na ilha. Essa falta de liberdade é que faz com que as pessoas da Ilha das Flores não sejam vistas como seres humanos.

O filme conclui seu quebra-cabeça interligando todos os conceitos mencionados didaticamente para que, ao final, sua poética seja visualizada como uma mensagem de conscientização de uma realidade desumana - tal qual a ênfase oposta em que vem a ser um ser 
humano. Mesmo com uma narrativa rápida e constante, tal documentário sai da zona de conforto para provocar reflexões acerca da individualidade, liberdade, opressão, exageros e desperdício.

\section{Aplicação de questionamentos baseados nos conceitos de Film Literacy}

Desde o início deste artigo viemos destacando o termo educação, tendo em vista que todos os processos e áreas se correlacionam e seus elementos constituintes se projetam às práticas em sala de aula. E, conforme já mencionado anteriormente no caso de Visual Literacy, se fôssemos traduzir literalmente o termo Film Literacy, teríamos uma "literacia fílmica", podendo ser confundida com um possível letramento. Assim, já que partimos da ideia de estabelecer o filme como dispositivo criativo, construtor de conhecimentos impulsionados pelo lúdico, tomaremos tal termo como "Filme-educação."

Queremos aqui destacar que o filme deve ser explorado em sala de aula, local onde ainda se apresenta certa resistência, devido à crença da visão cinematográfica de entretenimento exclusivamente. Almeida (2015) se posiciona da mesma forma ao mencionar que o encontro com o cinema no espaço educativo formal é cada dia mais importante, bem como Bergala (2008) quando salienta que "se o encontro da criança com diferentes narrativas fílmicas não ocorrer na escola, pode não acontecer em nenhum outro lugar" (BERGALA, 2008, p. 33).

Além disso, seu embasamento também está relacionado à prática e uso de filmes em sala de aula, interagindo com a cultura da imagem de maneira que comporta o fato de que “atualmente, há uma grande maioria de pessoas cuja inteligência foi e está sendo educada por imagens e sons, pela quantidade e qualidade de cinema e televisão a que assistem, e não mais pelo texto escrito" (ALMEIDA, 1994, p. 8). Assim, a aplicação das ideias do Film Literacy é relevante para a construção de métodos que se adequem e atendam as necessidades desse novo processo de aprendizagem pela imagética.

Para tanto, partiremos inicialmente com questionamentos em Five key questions that can change the world: lesson plans for media literacy (JOLLS; SHARE; THOMAN, 2005), como ferramenta para a realização de uma leitura fílmica. Tais questionamentos norteiam as principais preocupações do Film Literacy e revelam as potencialidades do filme que fomentarão uma possível discussão em sala de aula: 


\section{Quais técnicas criativas foram usadas para atrair a atenção?}

Os autores não especificam se tais técnicas são de âmbito geral ou específico da cinematografia. Compreendem-se aqui como artifícios que o filme fez uso para prender a atenção do espectador.

Montagem de maneira didática, de tal forma que a imagem retrata o que o texto está sendo dito. A sátira está nesta montagem que ora aponta de forma objetiva, ora ironiza o fato de como o ser humano pode estar em situações em que não é visto como ser humano. Muita coisa é dita, explicada e mostrada para, no fim, chegar ao problema da Ilha das flores.

\section{Como pessoas diferentes podem ver a mesma temática social de formas diferentes?}

Tal questionamento vai ao encontro da ideia de Akhras (2010), quando há variação de compreensão em razão da situação e contexto do aluno. Quando há diferentes contextos sociais, por exemplo, o filme pode ser entendido e decodificado de maneira diferente. Cabe ao professor nortear essas diferentes relações entre as situações distintas, como o questionamento do consumismo para um estudante de classe média e que tipo de identificação é gerado em um estudante de classe baixa quando questionado sobre a desigualdade social.

\section{Que tipo de valores, estilos de vida e pontos de vista são apresentados ou omitidos} pelo filme?

Como a vida é colocada de maneira desigual quando vista sob um enfoque econômico;

O ser humano, mesmo anatomicamente igual, não é colocado de maneira igual na ordem capitalista - por estar abaixo do porco;

Gera uma consciência social sobre como a economia influencia na vida do ser humano.

O filme apresenta valores claros e de forma consistente? Quais são seus pontos de vista?

O filme é objetivo e dinâmico em suas afirmações. Mesmo quando há ironia ou sátira, há um propósito de reflexão. Seus principais pontos de vista se focam em colocar, de uma maneira enfática, como a economia influencia nos valores sociais, e como a sua desigualdade é vivenciada de forma direta.

\section{Que tipo de mensagem o filme passa? Ela é feita claramente e de forma eficaz?}

O filme se preocupa em passar claramente a mensagem a respeito das desigualdades sociais existentes no país, bem como a falta de liberdade para aqueles que não são favorecidos economicamente. Há um protesto sutil e eficaz, cuja comoção não se dá pela voz neutra do 
narrador e sim pelas imagens impactantes. Com a inocente trajetória de um tomate, observamos o desenrolar do capitalismo e de um consumismo desenfreado que em suas consequências mais lamentáveis está o fato do ser humano estar abaixo dos animais e não ser livre.

Essas sucintas cinco questões podem ser capazes de ressaltar para o aluno a importância em ampliar a sua capacidade de ler filmes ou mesmo ampliar sua percepção do corpo e de como esse se insere no mundo, conforme defende Araújo (2013, p. 35-36):

\begin{abstract}
Ampliar a capacidade de leitura de filmes, através do conhecimento histórico do cinema, contribui para que a criança ou o jovem transforme sua forma de recepção das imagens. De um expectador passivo, que simplesmente assimila o que vê, esse passa a ser um expectador ativo. Pois, conhecer a origem das coisas, nos ajuda a compreender alguns porquês daquilo que está diante de nossos olhos.
\end{abstract}

De tal forma que o aprendizado com o cinema é a própria imersão em seus constituintes, não além da imagem, mas o que está transcrito nela. A Educação do Olhar se dá a partir daquilo que constitui o sujeito com a narrativa construída por seus elementos e escolhas artísticas. Bergala (2008) vai mais além quando diz que o filme não pode ser encarado como um simples objeto, e sim como a conclusão de um processo criativo e, por assim o considerar, um processo artístico. Ora, se há o discernimento que o diretor se baseou em escolhas na determinação de luzes, ângulos, etc., deve-se encarar o filme como um ato de criação. O "ler" não se limita a decodificar como a narrativa foi construída, e sim compreende o seu processo de criação.

A partir do momento em que são apresentados filmes com diferentes culturas e diversidades de nacionalidades conforme propõe Bergala (2012), há a capacidade de ampliação dessa leitura fílmica, ilustrando a eles as infinitas possibilidades que constituem a elaboração da narrativa. Tal atitude enriquece o senso crítico que deixa de ser limitado apenas pelo que o filme se propõe a tematizar, e vai além ao despertar as distintas belezas e riquezas do mesmo. Com isso, ao correlacionarmos os processos de aprendizagem com as questões que norteiam as ideias de Film Literacy, observamos as potencialidades fílmicas e suas possibilidades quando inseridas numa sala de aula. Portanto, cabe ao educador considerar o filme como além de uma narrativa audiovisual, e sim como um possível instrumento de embate cultural, de discussão, de contextualização, de aprendizagem e principalmente, de um propulsor de conhecimentos. 


\section{Referências}

AKHRAS, Fabio N. Uma perspectiva teórica para o documentário como cinema de aprendizado. Doc OnLine - Revista Digital de Cinema Documentário, Campinas, v. 9, p. 108-124, 2010.

ALMEIDA, M. Imagens e sons: a nova cultura oral. São Paulo: Cortez, 1994.

ALMEIDA, M. Prática educomunicativa como o cinema nas Licenciaturas. Comunicação \& Educação, São Paulo, v. 20, n. 2, p. 125-134, jul./dez. 2015.

ARAÚJO, A. A invenção de Hugo Cabret (HUGO). In: SAMPAIO, J. (Org.). Usando filmes nas aulas de arte. Curitiba: CRV, 2013.

BERGALA, Alain. Entrevista com Alain Bergala. Nova Escola, São Paulo, set. 2012. Disponível em: <https://novaescola.org.br/conteudo/922/entrevista-com-alain-bergala>. Acesso em: 17 maio 2017.

BERGALA, Alain. A hipótese-cinema: pequeno tratado de transmissão do cinema dentro e fora da escola. Rio de Janeiro: Booklink/CINEADLISE-FE/Uerj, 2008.

BRISTOR, V. J.; DRAKE, S. V. Linking the languages arts and content areas through visual technology. T.H.E. Journal, Chatsworth, CA, v. 22, n. 2, p. 74-77, 1994.

CASACINEPOA. Iha das Flores. Disponível em: <http://www.casacinepoa.com.br/os-filmes/roteiros /ilha-das-flores-texto-original>. Acesso em: 30 ago. 2017.

CASETTI, F. Teorie del cinema 1945-1990. Milano: Bompiani, 2004.

DUARTE, R. Cinema e educação. Belo Horizonte: Autêntica, 2002.

FANTIN, M. Crianças, cinema e mídia-educação: olhares e experiências no Brasil e na Itália. 2006. Tese (Doutorado em Educação) - Programa de Pós-Graduação em Educação, Universidade Federal de Santa Catarina, Florianópolis, 2006.

FANTIN, M. Cinema e imaginário infantil: a mediação entre o visível e o invisível. Educação e Realidade, Porto Alegre, v. 34, n. 2, p. 205-223, maio/ago. 2009.

ILHA das Flores. Direção de Jorge Furtado. Produção de Mônica Schmiedt, Giba Assis Brasil e Nôra Gulart. Roteiro de Jorge Furtado. Porto Alegre: Casa de Cinema de Porto Alegre, 1989. 1 videocassette (13 $\mathrm{min})$.

JOLLS, T.; SHARE, I.; THOMAN, E. Five key questions that can change the world: lesson plans for media literacy. Nova Iorque: CML, 2005.

KELLNER, D. Lendo imagens criticamente: em direção a uma pedagogia pós-moderna. In: SILVA, T. (Org.). Alienígenas na sala de aula: uma introdução aos estudos culturais na educação. Petrópolis: Vozes, 1995.

LINHARES, M.; PIMENTA, M. A pequena Miss Sunshine. In: SAMPAIO, J. (Org). Usando filmes nas aulas de arte. Curitiba: CRV, 2013.

MARTIN-BARBERO, J. Novos regimes de visualidade e descentralizações culturais. In: SECRETARIA DE EDUCAÇÃO A DISTÂNCIA. Mediatamente! Televisão, cultura e educação. Brasília: MEC/SEED, 1999.

MCLUHAN, M. Os meios de comunicação como extensões do homem. São Paulo: Cultrix, 1998.

SOUZA, E. Negritude, cinema e educação: os caminhos para a implementação da Lei 10.639/2003. 2. ed. Belo Horizonte: Mazza Edições, 2011. 
XAVIER, I. A experiência do cinema. Rio de Janeiro: Edições Graal; Embrafilme, 1983.

Pamela de Bortoli Machado - Universidade Estadual de Campinas - UNICAMP. Campinas | SP | Brasil. Contato: pam.dbmac@gmail.com

Fábio Nauras Akhras - Universidade Estadual de Campinas UNICAMP. Campinas | SP | Brasil. Contato: fabio.akhras@cti.gov.br

Artigo recebido em: 11 ago. $2016 \mathrm{e}$ aprovado em: 4 abr. 2017. 